\title{
Charting the NF-кB Pathway Interactome Map
}

\author{
Paolo Tieri ${ }^{1,2,3 *}$, Alberto Termanini ${ }^{1}$, Elena Bellavista ${ }^{1,2}$, Stefano Salvioli ${ }^{1,2}$, Miriam Capri ${ }^{1,2}$, Claudio \\ Franceschi ${ }^{1,2}$
}

1 CIG 'Luigi Galvani' Interdept Center, University of Bologna, Bologna, Italy, 2 Department of Experimental Pathology, University of Bologna, Bologna, Italy, 3 IAC-CNR Istituto per le Applicazioni del Calcolo, Consiglio Nazionale delle Ricerche, Rome, Italy

\begin{abstract}
Inflammation is part of a complex physiological response to harmful stimuli and pathogenic stress. The five components of the Nuclear Factor $\kappa B(\mathrm{NF}-\kappa \mathrm{B})$ family are prominent mediators of inflammation, acting as key transcriptional regulators of hundreds of genes. Several signaling pathways activated by diverse stimuli converge on NF- $\mathrm{B}$ activation, resulting in a regulatory system characterized by high complexity. It is increasingly recognized that the number of components that impinges upon phenotypic outcomes of signal transduction pathways may be higher than those taken into consideration from canonical pathway representations. Scope of the present analysis is to provide a wider, systemic picture of the NF- $\kappa B$ signaling system. Data from different sources such as literature, functional enrichment web resources, protein-protein interaction and pathway databases have been gathered, curated, integrated and analyzed in order to reconstruct a single, comprehensive picture of the proteins that interact with, and participate to the NF- $\mathrm{KB}$ activation system. Such a reconstruction shows that the NF- $\kappa B$ interactome is substantially different in quantity and quality of components with respect to canonical representations. The analysis highlights that several neglected but topologically central proteins may play a role in the activation of NF- $\mathrm{kB}$ mediated responses. Moreover the interactome structure fits with the characteristics of a bow tie architecture. This interactome is intended as an open network resource available for further development, refinement and analysis.
\end{abstract}

Citation: Tieri P, Termanini A, Bellavista E, Salvioli S, Capri M, et al. (2012) Charting the NF-אB Pathway Interactome Map. PLoS ONE 7(3): e32678. doi:10.1371/ journal.pone.0032678

Editor: Karen L. Mossman, McMaster University, Canada

Received November 3, 2011; Accepted January 28, 2012; Published March 5, 2012

Copyright: (c) 2012 Tieri et al. This is an open-access article distributed under the terms of the Creative Commons Attribution License, which permits unrestricted use, distribution, and reproduction in any medium, provided the original author and source are credited.

Funding: The research leading to these results has received funding from the European Union's Seventh Framework Programme (FP7/2007-2011) under grant agreements IDEAL ( ${ }^{\circ}$ 259679) and MYOAGE ( $\mathrm{n}^{\circ}$ 223576) to CF, and Roberto and Cornelia Pallotti Legacy for cancer research to CF and SS. The funders had no role in study design, data collection and analysis, decision to publish, or preparation of the manuscript.

Competing Interests: The authors have declared that no competing interests exist.

* E-mail: p.tieri@iac.cnr.it

\section{Introduction}

\section{Inflammation, a complex, pervasive process}

Inflammation is a complex, systemic, multi-scale physiological process necessary to cope with damaging agents and fundamental for survival, involving a variety of cells, organs and organ systems. The complexity of the inflammatory process has escaped reductionist and linear approaches, since it is characterized, among other features, by non-proportional kinetics as well as numerous and nested feedback loops [1]. Apart from its protective, physiological role, inflammation is an important concomitant cause of many major age-associated pathologies, such as cancer, neurodegeneration, Type II Diabetes and metabolic syndromes [2]. To this regard, it has been observed that a systemic, chronic, low-grade inflammatory status characterizes the aging process, and that markers of inflammation increase with age [3-7]. We proposed to indicate this phenomenon as "inflammaging" [8-10]. In this perspective, we hypothesised that the phenomenon of inflammaging, likely resulting from the chronic exposure to environmental stressors such as chronic viral infections [6,11], can be an important cause of these age-associated diseases, and therefore the genetic control of inflammation appears to be a crucial determinant of longevity, today a pressing topic given the aging of population all over the world.

A pivotal player of the inflammatory response is the $\mathrm{NF}-\kappa \mathrm{B}$ (nuclear factor kappa-light-chain-enhancer of activated B cells) transcription factor. Able to be activated by a great number of stimuli and to participate in the regulation of hundreds of genes $[12,13], \mathrm{NF}-\kappa \mathrm{B}$ has a wide spectrum of actions, such as to induce survival and proliferation, and in particular it is considered the master regulator of inflammation [14]. Thus, it is of great interest to deepen the basic knowledge regarding the topology and the dynamics of the signaling pathways and regulatory network underpinning the activation of such a pleiotropic transcription factor. While the literature dedicated to specific aspects of NF- $\kappa \mathrm{B}$ functions or regulation is huge, a wider representation of its complex regulating system is still missing.

\section{The NF- $\kappa B$ system}

$\mathrm{NF}-\kappa \mathrm{B}$ is a protein complex that both induces and represses gene expression by binding to discrete DNA sequences, known as $\kappa \mathrm{B}$ elements, in gene promoters and enhancers $[15,16]$. In mammalian cells, there are five NF- $\kappa \mathrm{B}$ family members, RelA

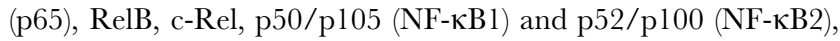
and different NF- $\kappa \mathrm{B}$ complexes are formed from their homo- and hetero-dimers. All proteins of the NF- $\mathrm{BB}$ family share a Rel homology domain. Moreover, RelA, RelB, and c-Rel have a transactivation domain in their $\mathrm{C}$-terminus required for gene

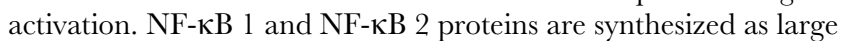
precursors, p105 and p100, which undergo processing to generate the mature NF- $\kappa \mathrm{B}$ subunits, p50 and p52, respectively. The 
processing of p105 and p100 is mediated by the ubiquitin/ proteasome pathway and involves selective degradation of their Gterminal region containing ankyrin repeats. Whereas the generation of p52 from p100 is a tightly-regulated process, p50 is produced from constitutive processing of p105 [16]. Additionally, the ubiquitin proteasome system controls NF- $\kappa \mathrm{B}$ activation also by the degradation of inhibitory proteins, including I $\mathrm{\kappa Bs}$ members, but there is evidence for different downstream level of NF- $\kappa \mathrm{B}$ regulation that employs several non proteolytic mechanisms, including promoter-specific exchange of dimers and modification of the transactivating p65 subunit by post translational modification, such as phosphorylation, acetylation and ubiquitination [17].

In vertebrates, NF- $\mathrm{KB}$ is activated by over 150 different stimuli, such as stress, cytokines, free radicals, ultraviolet irradiation, oxidized LDL and bacterial or viral antigens [12]. In turn, there is evidence that active $\mathrm{NF}-\kappa \mathrm{B}$ participates in the control of transcription of more than 400 genes [13]. These genes include cytokines, chemokines and their modulators, immunoreceptors, proteins involved in antigen presentation, cell adhesion molecules, acute phase proteins, stress response proteins, cell-surface receptors, regulators of apoptosis, growth factors, ligands and their modulators, early response proteins, transcription factors and regulators, and enzymes, controlling several phenomena such as inflammation as well as innate and adaptive immune response [16]. Considering the central role of NF- $\mathrm{KB}$ in maintaining cellular homeostasis, it is not surprising that dysregulation of its finely tuned modulation has often been linked to the development of several disorders, most of which with an inflammatory component such as cancer, autoimmune diseases, and chronic inflammatory disorders $[18,19]$.

Twenty-five years of research efforts [20] have not been enough for a sufficient comprehension of NF- $\kappa \mathrm{B}$ dynamics [21], and gaining insights into NF- $\mathrm{KB}$ and related processes is still a top priority for the understanding of the onset of associated diseases [20].

\section{Moving from NF- $\kappa B$ pathway to NF- $\kappa B$ interactome network}

It is increasingly recognized that the number of components that impinge upon phenotypic outcomes of signal transduction pathways may be higher than that taken into consideration from canonical representations [22-24]. Indeed, recent screens suggest the participation of hundreds of components, instead of the dozens classically involved in canonical signaling pathway representations [22], proposing a switch from linear or branched signal cascades to networks with complex interdependencies and feedbacks. Moreover, the interpretation of new findings [23] suggests that cell functionality may be based on a single "mega-network with limited isolation" [22] between pathways' elements, modules (i.e. a set of proteins capable of independent functionality) and networks. The difficulty in drawing contours and boundaries of signaling pathways becomes more evident when the study of the system is approached with formal engineering failure analysis [25]. Systems biology approaches may provide crucial clues about the architecture and the logic of the regulation of the NF- $\mathrm{KB}$ system and related gene expression [20]. Moreover, comprehensive maps of complex signaling pathways are proving to be important tools to facilitate systems-level study [26,27].

Signaling crosstalk and combinatorial control of NF- $\mathrm{BB}$ pathway are very complex [28-31]. In-depth studies often report fragmented knowledge, since they forcedly focus only on a limited part of the puzzle. In this scenario limiting analyses to canonical $\mathrm{NF}-\kappa \mathrm{B}$ pathway elements may reveal inadequate in unveiling crucial mechanisms or players in the regulation of this system. The aim of this work is to integrate into one single, more comprehensive and less "pathway-centric" [22] picture all the proteins that, on the basis of present knowledge, interact directly or indirectly with the fundamental NF- $\kappa \mathrm{B}$-activation proteins to compose the "NF- $\mathrm{B}$ pathway interactome". We propose that such approach may give further insights on the contribution of components that would have been neglected in a more canonical perspective. Such a comprehensive approach may provide insights about how specific stimuli trigger particular subsets of NF- $\mathrm{BB}$ target genes [21], or about the regulatory hierarchy that rules the selection of target gene expression [32]. To do this, we mined from multiple sources and integrated in an unitary view manually collected data from literature, binary protein-protein interaction (PPI) data, protein annotation data, and NF- $\mathrm{BB}$ downstream genes data. We compiled three different sets of proteins that show evidence of involvement in the upstream regulation process of NF$\kappa \mathrm{B}$, and one set of downstream genes (and related proteins) which expression appears to be regulated by NF- $\kappa \mathrm{B}$. Starting from these sets, we reconstructed three $\mathrm{NF}-\kappa \mathrm{B}$ protein interaction networks (PINs), or interactomes, by using PPI data from multiple databases, and then checked for the existence of physical interactions between these upstream protein sets and the downstream set. The resulting interactomes also underwent functional enrichment and network analysis to highlight their composition and structure.

\section{Materials and Methods}

Part of data retrieval, interactome reconstruction and analysis have been performed with the use of the Cytoscape network analysis platform [33-35] and following a general workflow also described in [36]. For PPI data and interactome reconstruction, we used the Agile Protein Interaction Database (APID) [37], a comprehensive resource for protein interaction data, automatically accessed by Cytoscape through the dedicated plugin APID2NET [38]. APID integrates in a single web-based tool all known experimentally validated protein-protein interactions from BIND, BioGRID, DIP, HPRD, IntAct and MINT databases. Annotation and pathway data have been collected mainly from the Universal Protein Resource (UniProt) and the Kyoto Encyclopedia of Genes and Genomes (KEGG), accessed through the suites FaTiGO [39] and Babelomics [40,41]. Additional information on disease pathways have been accessed through DisGeNET [42], and the Pharmacogenomics Knowledge Base PharmGKB [43]. All databases and platforms used here are free and open access. The complete protein lists and relative analysis results are provided in tables $\mathrm{S} 1, \mathrm{~S} 2, \mathrm{~S} 3$ and dataset $\mathrm{S} 1$. Note that we refer to a "set" as to a list of proteins, and to "interactome" as to a network whose elements are (all or a part of) the proteins of the respective set, enriched with the available protein interaction data. Interactome acronyms are indicated with a capital "I" after the acronym of the respective set.

The network analysis have been performed using the Cytoscape platform and the plugins Networkanalyzer [44] and MCODE [45]. Besides classical parameters (node degree and betweenness centrality, among others), we also calculated the network density (the average number of neighbors for each node), and the network centralization. The degree of a node is the number of edges linked to it. In this case, it is the number of physical interactions that a specific protein shows with other proteins. The betweenness centrality of a node attests the grade of control that this node exerts over the interactions of other nodes in the network, and its biological relevance has been demonstrated [46,47]. The average number of neighbours (connectivity) of a node in the network may 

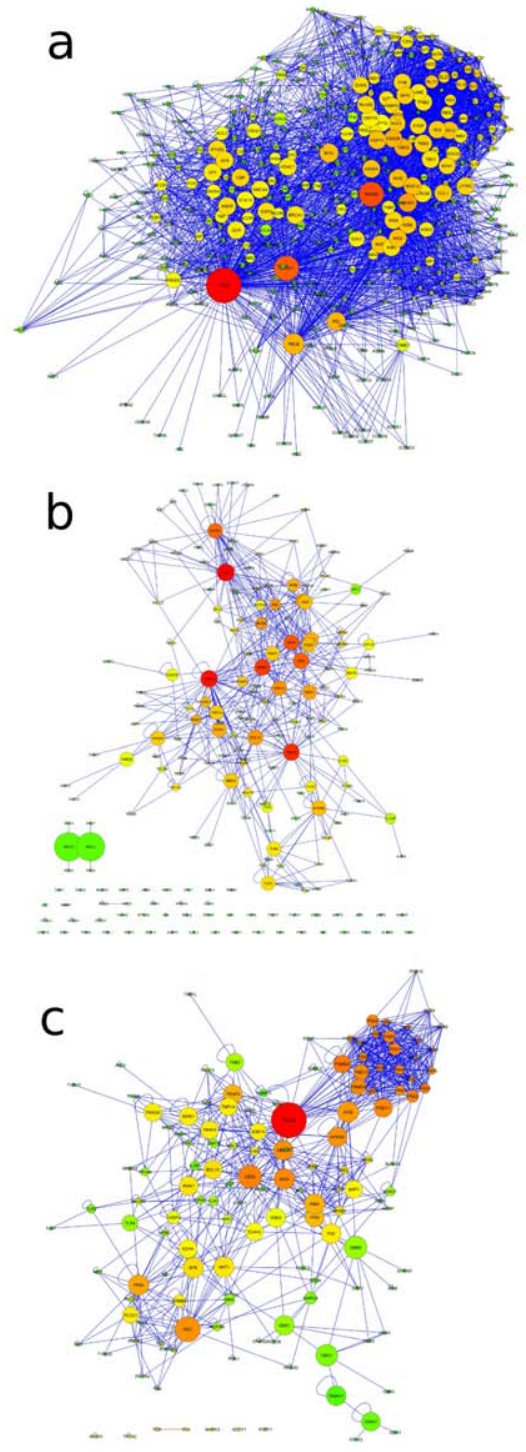

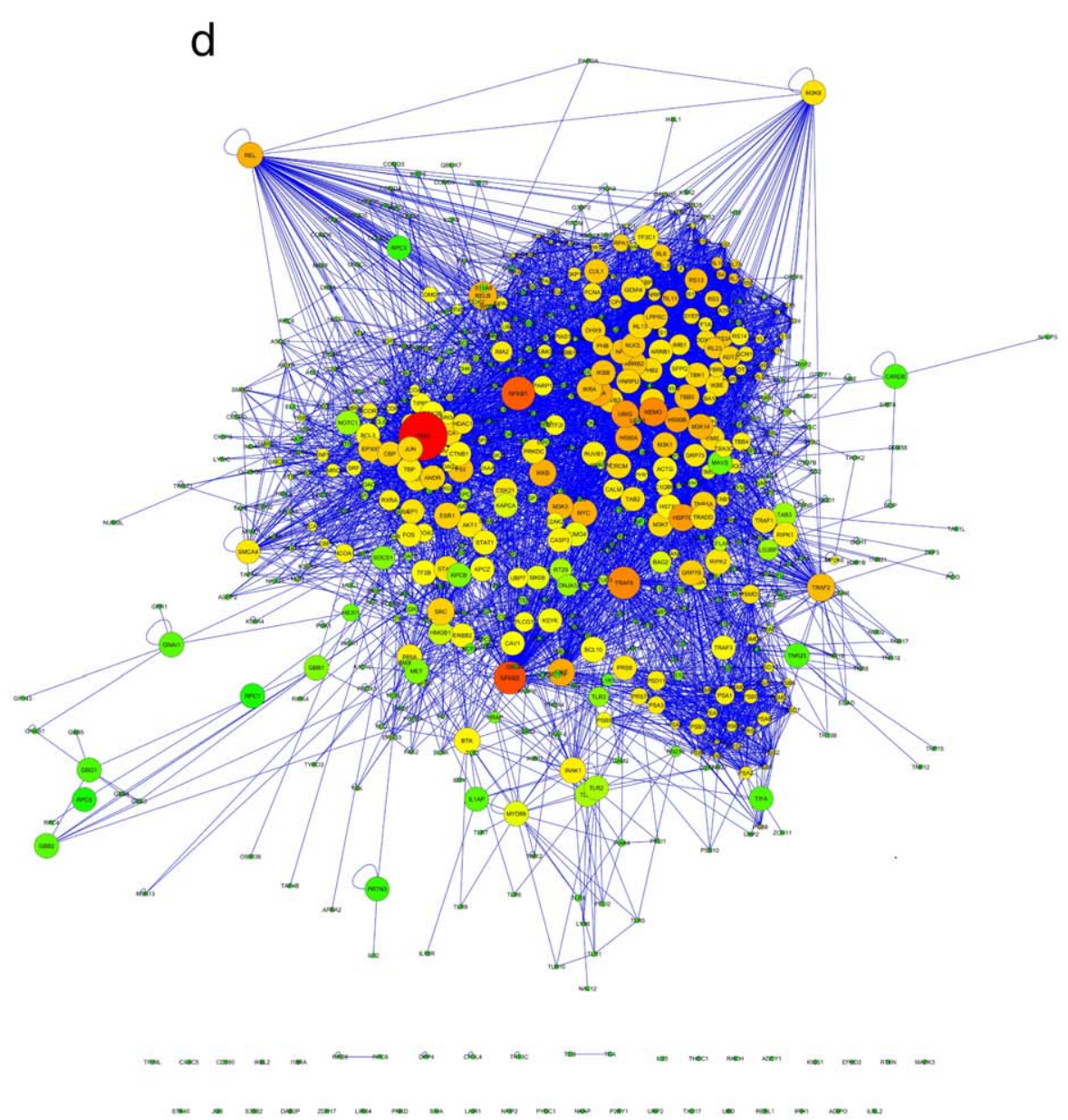

Figure 1. The three interactomes $\mathrm{DI}(\mathrm{a}), \mathrm{UI}(\mathrm{b})$ and $\mathrm{MCI}$ (c) and the resulting UNION interactome (d) as from Cytoscape layout, available in the Dataset S1 as .cys file. Datasets and interactomes have been reconstructed following procedures described in materials and methods section. Nodes represent proteins and links are evidence-based physical interactions. Node size and color are proportional to betweenness centrality values (red: high, green: low; not comparable among different interactomes). Isolated proteins show no evidence of physical interactions with any other proteins within the same dataset.

doi:10.1371/journal.pone.0032678.g001

also be represented by means of a normalized version of this parameter, i.e. the network density. The density is a value between 0 and 1 , and shows how densely the network is populated with links. In calculating density, self-loops are ignored (self-loops are evidence based interactions between two copies of the same protein [44]). Network centrality is a parameter which value ranges between 0 and 1 . Networks whose topologies resemble a star (i.e. with a relatively well defined central core) have a centrality close to 1 , whereas decentralized networks are characterized by having a centrality close to 0 . The interactomes are completely available in Cytoscape format (.cys) in the Dataset S1.

\section{Directly Interacting (DI) NF- $\kappa$ B proteins dataset}

The directly-NF- $\mathrm{BB}$-interacting protein set, or hereinafter Direct Interactome, (DI) (fig. la), is composed by all the proteins that show experimental evidence of physical interaction with at least one of the five NF- $\mathrm{BB}$ members. Given the procedure used (search for directly NF- $\mathrm{KB}$-interacting proteins), in the case of DI, the protein set coincides with the respective interactome. Data retrieval has been performed with APID2NET and Cytoscape. The query returned a total of 377 proteins (including the five NF$\kappa \mathrm{B}$ members). The DI accounts for 4,119 non-directional interactions (including self-interactions).

\section{Uniprot (U) NF- $\kappa B$ annotated proteins dataset}

To populate the set $\mathrm{U}$, we searched the UniProt Knowledge Base with the parameters: «annotation:(type: nompositional "nf kappa b") and organism: "Homo sapiens (Human) [9606]"' and we retrieved a list of 235 proteins that have been manually screened and checked to obtain a final, validated list of 229 proteins with evidence of implications in the NF- $\kappa \mathrm{B}$ functioning (see Table $\mathrm{S} 1$ for 


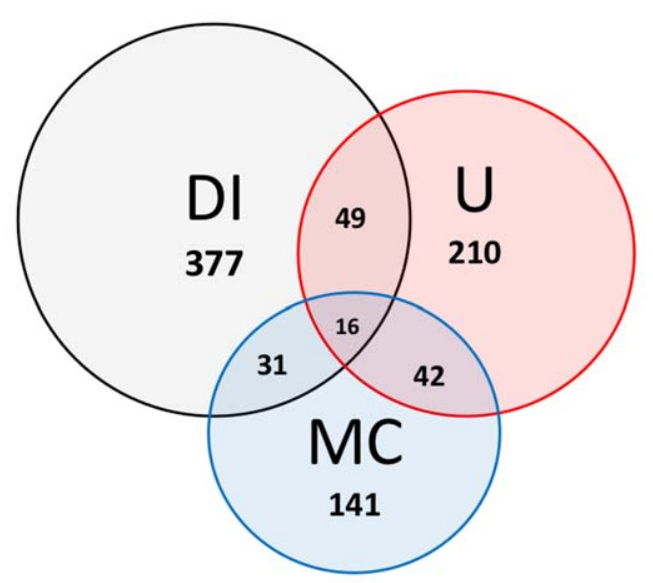

Figure 2. Datasets $\mathrm{DI}, \mathrm{U}$ and $\mathrm{MC}$ share a relatively low number of proteins, as reported by the figures in the intersections. Datasets are quite differentiated in their composition and share only the $2.6 \%$ of the whole UNION set (16 out of 622 ).

doi:10.1371/journal.pone.0032678.g002

description). Starting from this set, experimental protein interaction data are retrieved in order to reconstruct the relative interactome. Two hundred and ten proteins (210), out of 229, are present in the APID database, from which interaction data have been downloaded, and constitute the Uniprot interactome (UI, fig. 1b). One hundred and fifty proteins (out of 210) form a main cluster, accounting for 550 interactions, while other 60 are isolated from the main cluster.

\section{Manually Curated (MC) proteins dataset}

We selected and then manually screened a collection of 37 top quality, highly cited literature papers regarding $\mathrm{NF}-\kappa \mathrm{B}$ to identify proteins that take part with different roles and functions to the signalling cascade leading to NF- $\mathrm{BB}$ activation [14,17,48-82]. The criteria for protein selection and inclusion in the $\mathrm{MC}$ set are based on its presence and function described in each paper, either as directly involved in the cascade dynamics (e.g. interacting protein), or collaterally participating with a function identified and described in the articles considered. One hundred and forty one proteins (141) have been identified. Again, PPI data have been added (through the use of the APID database) to build the Manually Curated interactome (MCI), that accounts for 853 nondirectional interactions (including self-interactions) (fig. 1c). All proteins in the DI, $\mathrm{U}$ and MC sets are considered to work upstream $\mathrm{NF}-\kappa \mathrm{B}$, i.e. to participate with a variable role to the modulation and to the signalling cascade leading to NF$\kappa$ Bactivation.

\section{Downstream Genes (DG) dataset}

Data extracted from a manually curated list of NF- $\mathrm{BB}-$ downstream genes (www.nf-kb.org; [13]) and from the Transcriptional Regulatory Elements Database (TRED; [83,84]) constitute a list of 441 genes that result to be up- or down-regulated in response to the activation of at least one of the NF- $\kappa \mathrm{B}$ family members (Table S2). Four hundred forty one (441) valid ENSEMBL gene identifiers mapping to 426 related protein unique identifiers (Uniprot IDs) have been obtained using online ID converter tools [85]. The Babelomics suite for functional analysis identified 16 duplicates leading to a valid list of 410 IDs. Three hundred and eighty four (384) out of 426 protein IDs have been found in the APID database, used for DG interactome reconstruction.

\section{Results}

\section{Composition and analysis of the protein sets and interactomes}

The three sets DI, U and MC (and corresponding interactomes DI, UI and MCI) show substantial differences with one another in their dimensions and structure as well as in the protein composition. We also considered the interactome resulting from the union of DI, UI and MCI (DI $\cup$ UI $\cup$ MCI; hereinafter UNION, Figure 1d), which accounts for 622 proteins and 6,115 interactions (see table 1 for the main parameters) in order to have the widest possible picture of the elements participating in the NF$\kappa \mathrm{B}$ system. The intersection of all three sets (the proteins shared by all three sets: DI $\cap$ UI $\cap$ MCI) accounts for only 16 proteins and 89 interactions (see fig. 2 and Dataset S1). The intersection should represent the very "core" of the system. Indeed it contains the 5 members of the NF-kB family (p65, RelB, c-Rel, NF- $\kappa$ B1, NF$\kappa \mathrm{B} 2)$, the 4 members of the inhibitor of NF- $\kappa \mathrm{B}(\mathrm{I} \kappa \mathrm{B})$ family $(\mathrm{I} \kappa \mathrm{B} \alpha$, $\mathrm{I} \kappa \mathrm{B} \beta, \mathrm{I} \kappa \mathrm{B} \varepsilon, \mathrm{BCL}-3)$ and the three core subunits of the I $\kappa \mathrm{B}$ kinase (IKK) complex (NEMO, IKK $\alpha, \operatorname{IKK} \beta$ ) as reported by Perkins [14]. Other components of this core subset are IKBKE, MAP3K14, TRAF3 and NKRF, which are very well known elements able to activate or inhibit NF- $\mathrm{KB}$ [86-89]. The MCI is the most dense and less populated by self-loops, while the UNION shows high average neighbours value but also many self-loops (Table 1). The most centralised interactome is the DI, while the UI is the most decentralized (Table 1).

Network analysis showed that, as expected, being these networks centred on NF- $\kappa \mathrm{B}$, the five NF- $\kappa \mathrm{B}$ subunits are among the most central elements for betweenness centrality values (Table 2). This condition is common to all 3 interactomes. The betweenness centrality of a node attests the amount of control exerted by this node over the capability of interaction of other nodes in the network. In particular, four out of five $\mathrm{NF}-\kappa \mathrm{B}$ components are in the first five positions for betweenness centrality in the UNION set (table 2; complete list available in Dataset $\mathrm{S} 1$ ), while REL is ranked $21^{\text {st }}$. Among the highest ranking proteins, TRAF6, at third position, is the element of connection of crucial membrane receptors. It is a member of the TNF receptor associated factor (TRAF) protein family, and mediates signal transduction from members of the TNF receptor superfamily and of the Toll/IL-1 family [90]. The connection between these two receptor families is interesting because the Toll-Like Receptors (TLRs) and TNF receptors (TNFRs) play the role of external sensors for NF- $\kappa \mathrm{B}$ pathway activation. TLRs take a crucial part in early host defense against invading pathogens, recognizing many pathogen-associated molecular patterns (PAMPs), including bacterial cell-surface lipopolysaccharides, peptidoglycans and lipoproteins, viral double-stranded RNA and viral single-stranded RNA, bacterial and viral CpG, as recently reviewed [91]; TNFR is the mediator of TNF effects, one of the universal effectors of innate signaling, involved in host defense and inflammation [92].

Table 2 also shows that three broad activators of gene transcription such as Myc, p53 and STAT3 are found as central elements at position 13, 20 and 25, respectively. This reflects the fact that NF- $\kappa \mathrm{B}$ is not only important for linking adaptive and innate immunity but it is also at the very centre of fundamental cell defense mechanisms such as stress response, as well as of other basic cellular functions such as survival and proliferation, thus confirming its primordial role as central actor in the protection of a multicellular organism's integrity [21]. Interestingly, the highly conserved protein UBIQ (ubiquitin) ranks at position 9 (Table 2), while other well-known inhibitors of NF$\kappa \mathrm{B}, \mathrm{IKKB}, \mathrm{IKKE}$, IKKA and IKBA rank at position 10, 12, 16 and 24 , respectively. The presence at such top ranking positions of factors 
Table 1. summary of main network parameters of NF- $\mathrm{KB}$ upstream protein interactomes $\mathrm{DI}, \mathrm{UI}, \mathrm{MCI}$ and $\mathrm{UNION}$ and overrepresented KEGG pathways $(p<0.05)$.

\begin{tabular}{|c|c|c|c|c|c|c|c|}
\hline $\begin{array}{l}\text { Intera } \\
\text { ctome }\end{array}$ & $\begin{array}{l}\text { No of } p \\
\text { roteins }\end{array}$ & $\begin{array}{l}\text { No of } \\
\text { interactions }\end{array}$ & $\begin{array}{l}\text { Avg } \\
\text { neigbours/ } \\
\text { density }\end{array}$ & Centraliz & Main overrepresented KEGG pathways & $\begin{array}{l}\text { \% of pathway } \\
\text { covered }\end{array}$ & $\begin{array}{l}\% \text { of } \\
\text { interactome }\end{array}$ \\
\hline \multirow[t]{10}{*}{ DI } & 377 & 4119 & 21.1/0.056 & 0.591 & hsa03010 Ribosome & 28.8 & 7.2 \\
\hline & & & & & hsa03050 Proteasome & 21.8 & 3.2 \\
\hline & & & & & hsa04623 Cytosolic DNA-sensing pathway & 21.4 & 3.2 \\
\hline & & & & & hsa04622 RIG--like receptor signaling pathway & 19.7 & 4.0 \\
\hline & & & & & hsa05215 Prostate cancer & 18.9 & 4.5 \\
\hline & & & & & hsa04621 NOD-like receptor signaling pathway & 18.9 & 3.5 \\
\hline & & & & & hsa04662 B cell receptor signaling pathway & 18.7 & 3.7 \\
\hline & & & & & hsa04920 Adipocytokine signaling pathway & 18.0 & 3.7 \\
\hline & & & & & hsa04620 Toll-like receptor signaling pathway & 17.6 & 5.0 \\
\hline & & & & & hsa03020 RNA polymerase & 17.1 & 1.6 \\
\hline \multirow[t]{10}{*}{$\mathbf{u}$} & 210 & 568 & $4.6 / 0.022$ & 0.185 & hsa04623 Cytosolic DNA-sensing pathway & 40.0 & 9.6 \\
\hline & & & & & hsa04622 RIG-I-like receptor signaling pathway & 32.0 & 10.5 \\
\hline & & & & & hsa04621 NOD-like receptor signaling pathway & 29.4 & 8.7 \\
\hline & & & & & hsa04620 Toll-like receptor signaling pathway & 26.2 & 12.2 \\
\hline & & & & & hsa03020 RNA polymerase (22.9) & 22.9 & 3.5 \\
\hline & & & & & hsa04210 Apoptosis & 18.5 & 7.4 \\
\hline & & & & & hsa04662 B cell receptor signaling pathway & 17.6 & 5.7 \\
\hline & & & & & hsa04920 Adipocytokine signaling pathway & 16.9 & 5.7 \\
\hline & & & & & hsa05222 Small cell lung cancer & 14.4 & 5.7 \\
\hline & & & & & hsa04660 T cell receptor signaling pathway & 13.2 & 6.6 \\
\hline \multirow[t]{10}{*}{ MC } & 141 & 853 & $11.0 / 0.078$ & 0.232 & hsa03050 Proteasome & 54.0 & 19.2 \\
\hline & & & & & hsa04210 Apoptosis & 27.2 & 17.7 \\
\hline & & & & & hsa04662 B cell receptor signaling pathway & 21.6 & 11.4 \\
\hline & & & & & hsa04620 Toll-like receptor signaling pathway & 20.6 & 15.6 \\
\hline & & & & & hsa04622 RIG-I-like receptor signaling pathway & 20.0 & 10.6 \\
\hline & & & & & hsa04621 NOD-like receptor signaling pathway & 19.1 & 9.2 \\
\hline & & & & & hsa05222 Small cell lung cancer & 17.8 & 11.4 \\
\hline & & & & & hsa04920 Adipocytokine signaling pathway & 16.9 & 9.2 \\
\hline & & & & & hsa04660 T cell receptor signaling pathway & 16.7 & 13.5 \\
\hline & & & & & hsa04722 Neurotrophin signaling pathway & 16.7 & 14.9 \\
\hline \multirow[t]{10}{*}{ UNION } & 622 & 6115 & $18.9 / 0.030$ & 0.360 & hsa03050 Proteasome & 62.0 & 5.0 \\
\hline & & & & & hsa04621 NOD-like receptor signaling pathway & 40.6 & 4.5 \\
\hline & & & & & hsa04620 Toll-like receptor signaling pathway & 38.0 & 6.6 \\
\hline & & & & & hsa04623 Cytosolic DNA-sensing pathway & 37.5 & 3.4 \\
\hline & & & & & hsa03020 RNA polymerase & 34.3 & 1.9 \\
\hline & & & & & hsa04622 RIG-I-like receptor signaling pathway & 34.2 & 4.2 \\
\hline & & & & & hsa04210 Apoptosis & 33.3 & 5.0 \\
\hline & & & & & hsa04662 B cell receptor signaling pathway & 30.7 & 3.7 \\
\hline & & & & & hsa05222 Small cell lung cancer & 29.7 & 4.3 \\
\hline & & & & & hsa03010 Ribosome & 28.7 & 4.3 \\
\hline
\end{tabular}

See main text for further comments and explanations. Complete datasets available in Table S3.

doi:10.1371/journal.pone.0032678.t001

that inhibit NF- $\mathrm{\kappa B}$ or target it to proteasomal degradation is a further indication of the centrality of this complex, which, due to its pleiotropic effects, must be tightly controlled [93].

We observed a limited degree of overlapping among the sets (Fig. 2): DI and U share only the $9.1 \%$ of their elements, DI and
MC the $6.4 \%$, $\mathrm{U}$ and $\mathrm{MC}$ the $13.6 \%$, while only the $2.6 \%$ of the elements are shared by all three interactomes (16 out of 622 ). These numbers partly reflect the difference and dishomogeneity in sources, databases, data types and relative retrieval method that have been used. Nevertheless, we did not expect such remarkable 
Table 2. First 25 most central proteins (betweenness centrality) in UNION interactome (in bold the NF- $\kappa B$ components).

\begin{tabular}{|c|c|c|c|c|}
\hline Rank & Protein ID & Betwn Centr & Protein description & NCBI gene name \\
\hline 1 & TF65 & 0.21071004 & Transcription factor p65 & RELA \\
\hline 2 & NFKB1 & 0.08342206 & Nuclear factor NF-kappa-B p105 subunit & NFKB1 \\
\hline 3 & TRAF6 & 0.07545745 & TNF receptor-associated factor 6 & TRAF6 \\
\hline 4 & NFKB2 & 0.07071487 & Nuclear factor NF-kappa-B p100 subunit & NFKB2 \\
\hline 5 & RELB & 0.0393886 & Transcription factor RelB & RELB \\
\hline 6 & NEMO & 0.03913555 & NF-kappa-B essential modulator & IKBKG \\
\hline 7 & TRAF2 & 0.03567854 & TNF receptor-associated factor 2 & TRAF2 \\
\hline 8 & SRC & 0.03049217 & Proto-oncogene tyrosine-protein kinase Src & SRC \\
\hline 9 & UBIQ & 0.02940406 & Ubiquitin & RPS27A \\
\hline 10 & IKKB & 0.02905882 & Inhibitor of nuclear factor kappa-B kinase subunit beta & IKBKB \\
\hline 11 & HSP7C & 0.02826285 & Heat shock cognate $71 \mathrm{kDa}$ protein & HSPA8 \\
\hline 12 & IKKE & 0.02712651 & Inhibitor of nuclear factor kappa-B kinase subunit epsilon & IKBKE \\
\hline 13 & MYC & 0.0253939 & Myc proto-oncogene protein & MYC \\
\hline 14 & $\mathrm{HS90A}$ & 0.02399683 & Heat shock protein HSP 90-alpha & HSP90AA1 \\
\hline 15 & ESR1 & 0.02195341 & Estrogen receptor & ESR1 \\
\hline 16 & IKKA & 0.02094338 & Inhibitor of nuclear factor kappa-B kinase subunit alpha & CHUK \\
\hline 17 & BTK & 0.0202242 & Tyrosine-protein kinase BTK & BTK \\
\hline 18 & IRAK1 & 0.01966103 & Interleukin-1 receptor-associated kinase 1 & IRAK1 \\
\hline 19 & М3К3 & 0.01862895 & Mitogen-activated protein kinase kinase kinase 3 & MAP3K3 \\
\hline 20 & P53 & 0.0165347 & Tumor suppressor gene p53 & TP53 \\
\hline 21 & REL & 0.01543792 & C-Rel proto-oncogene protein & REL \\
\hline 22 & RIPK2 & 0.01533207 & Receptor-interacting serine/threonine-protein kinase 2 & RIPK2 \\
\hline 23 & BCL10 & 0.01434518 & B-cell lymphoma/leukemia 10 & BCL10 \\
\hline 24 & IKBA & 0.01433697 & NF-kappa-B inhibitor alpha & NFKBIA \\
\hline 25 & STAT3 & 0.01373161 & Signal transducer and activator of transcription 3 & STAT3 \\
\hline
\end{tabular}

doi:10.1371/journal.pone.0032678.t002

discrepancy in the composition of the sets, discrepancy that might not be totally explained simply taking into account the wide differences in data sources and the integrative approach used, but, on the contrary, should cast some doubts about the adequacy and the completeness of the classical pathway descriptions.

Another example of such inadequacy is the fact that from the analysis of the datasets TAK1 (MAP3K7) did not result to be high ranking, as it would be expected [94].

By using the Babelomics platform, we analyzed all the sets to identify the metabolic or signalling pathways which elements are shared with the given sets. In Table 1 we show the first ten overrepresented pathways in the DI, U, MC and UNION according to this analysis. The complete lists of KEGG significant terms ( $\mathrm{p}-$ value $<0.05)$ are available in the Table S3. We noted that 5 KEGG pathways resulted as ranking within the top 10 in DI, U, and $\mathrm{MC}$, and that 4 out of 5 are pathways linked to the induction of innate immunity response and inflammation (Toll-like receptor signaling pathway; RIG-I-like receptor signalling pathway; NODlike receptor signalling pathway; Adipocytokine signalling pathway). This confirms that, even if the sources of these sets are very different, our analysis was able to capture the role of NF- $\mathrm{NB}$ as mediator of inflammation. Interestingly, MAPK pathway ranks always high in terms of percentage of proteins present in all three protein sets, indicating that also signal transduction leading to NF$\mathrm{\kappa B}$ activation is a process whose component are captured by our analysis. The UNION set resumes the characteristics of the three and represents, in number of components, $62 \%$ of the whole
KEGG-annotated proteasome and $41 \%$ of the NOD signalling pathway, among others.

\section{Downstream gene and protein set: composition and characteristics}

The same KEGG analysis has been done on NF-кB downstream gene set (410 out of 426 identifiers have been recognized by the Babelomics analysis suite). Among the top 10 identified pathways (Table 3), four are involved in inflammation (Toll-like receptor signalling pathway; NOD-like receptor signalling pathway; cytosolic DNA-sensing pathway; cytokine-cytokine receptor interaction), with two of them also shared by the DI, U and MC sets. The analysis has also pointed out that relevant subsets of DG are related to pathologies with well-known inflammatory aetiology, such as bladder and prostate cancers, among others.

We noted that 49 proteins are present in both UNION and DG sets (Table 4), thus meaning that $13 \%$ of the identified NF-кBregulated genes express proteins that play a direct role in the UNION interactome (Figure 3). These data suggest that the implication of such feedback loop in the dynamics of the interactome and in its regulation and activation of NF- $\kappa \mathrm{B}$ may be remarkable. The ability of $\mathrm{NF}-\kappa \mathrm{B}$ to control the transcription of a non negligible part of its activation pathway interactome surely deserves a deeper attention. Since NF- $\kappa B$ is a constitutively expressed protein complex, and since it has a crucial importance in the regulation of fundamental tasks such as the immune responses 
Table 3. Overrepresented pathways in DG $(p<0.05)$, first 20 terms ranked for percentage of DG proteins present in KEGG pathway ("\% of set" column).

\begin{tabular}{|c|c|c|c|c|c|}
\hline KEGG ID & Pathway & Total terms in KEGG pathway & Terms in set and pathway & $\%$ of set & $\%$ of pathway \\
\hline hsa04060 & Cytokine-cytokine receptor interaction & 271 & 70 & 17,07 & 25,83 \\
\hline hsa04062 & Chemokine signaling pathway & 186 & 30 & 7,32 & 16,13 \\
\hline hsa04630 & Jak-STAT signaling pathway & 154 & 26 & 6,34 & 16,88 \\
\hline hsa04620 & Toll-like receptor signaling pathway & 101 & 23 & 5,61 & 22,77 \\
\hline hsa05222 & Small cell lung cancer & 90 & 19 & 4,63 & 21,11 \\
\hline hsa04621 & NOD-like receptor signaling pathway & 62 & 17 & 4,15 & 27,42 \\
\hline hsa05215 & Prostate cancer & 88 & 17 & 4,15 & 19,32 \\
\hline hsa04210 & Apoptosis & 86 & 16 & 3,90 & 18,60 \\
\hline hsa04940 & Type I diabetes mellitus & 90 & 16 & 3,90 & 17,78 \\
\hline hsa04672 & Intestinal immune network for IgA production & 84 & 15 & 3,66 & 17,86 \\
\hline hsa05330 & Allograft rejection & 84 & 15 & 3,66 & 17,86 \\
\hline hsa04640 & Hematopoietic cell lineage & 87 & 15 & 3,66 & 17,24 \\
\hline hsa05332 & Graft-versus-host disease & 87 & 13 & 3,17 & 14,94 \\
\hline hsa05219 & Bladder cancer & 42 & 12 & 2,93 & 28,57 \\
\hline hsa04115 & p53 signaling pathway & 67 & 11 & 2,68 & 16,42 \\
\hline hsa05218 & Melanoma & 70 & 11 & 2,68 & 15,71 \\
\hline hsa05212 & Pancreatic cancer & 71 & 11 & 2,68 & 15,49 \\
\hline hsa04623 & Cytosolic DNA-sensing pathway & 55 & 10 & 2,44 & 18,18 \\
\hline hsa05340 & Primary immunodeficiency & 41 & 9 & 2,20 & 21,95 \\
\hline hsa05014 & Amyotrophic lateral sclerosis & 57 & 9 & 2,20 & 15,79 \\
\hline
\end{tabular}

doi:10.1371/journal.pone.0032678.t003

and inflammation, it must be tightly self-regulated to prevent malfunctions and inappropriate activation.

Several feedback loops are already well-known and studied in the literature, while many others have not been taken under consideration in the perspective of the possible implications in the regulation of the $\mathrm{NF}-\kappa \mathrm{B}$ pathway dynamics. In fact, as already reported in literature and confirmed by our analysis (Table 4), NF$\kappa \mathrm{B}$ complexes directly control the expression of their own subunits with the exception of TF65 [14]. Thus, NF- $\kappa$ B system appears to be very tightly self-regulated.

\section{Discussion}

As mentioned in the introduction, an increase of inflammatory markers has been described as a general feature of the ageing process and proposed as a possible cause of many age-associated diseases. Therefore, the system of NF- $\mathrm{BB}$ is likely a crucial player in this process. In this perspective, in order to understand how the changes in composition and abundance of the NF- $\mathrm{\kappa B}$ interactome can regulate NF- $\mathrm{BB}$ activation, and thus (at least in part) the ageing process, the knowledge about NF- $\kappa \mathrm{B}$ pathway as well as the proteins that can interact directly or indirectly with it must be broaden. To this purpose, we integrated data from multiple existing sources in order to chart the NF-кB interactome map. Our map may help in improving the understanding of complex signalling networks and highlights the impact of single elements, their feedback and crosstalk regulations on cellular processes [26]. Beside confirming previous studies and insights [22], the integrative effort proposed here in merging existing, freely available data highlights that the number of elements impinging upon NF- $\mathrm{KB}$-activating pathway outcomes is much higher than that usually taken under consideration in canonical pathway representations.
Furthermore, as other pleiotropic factors that receive many inputs and spread out many outputs, NF- $\kappa \mathrm{B}$ core elements are at the centre of a network characterised by a bow tie architecture [95], with a fan in (UNION interactome), a knob (the NF-кB family), a fan out (downstream genes modulated by NF- $\kappa \mathrm{B}$ ) and feedback loops. This is not surprising, since the bow tie might represent an economical and efficient way to convey on the same target different stimuli to which cells and organs are exposed $[95,96]$. Moreover, bow tie architecture may be an advantageous solution for the evolution of complex systems, because it would minimize the number of central molecular mediators, ultimately reducing energy expenditure for both the integration of stimuli and the determination of the outcome $[97,98]$. Bow ties are considered to be fundamental in explaining the coexistence of robustness and evolvability in complex systems due to their ability to facilitate control [95,99-102]. Another striking feature of bow ties' functioning is their inner resilience characterised by the presence of regulatory feedback loop, i.e. some products of the fan out are also part of the fan in. In this case the NF- $\kappa \mathrm{B}$ system fits perfectly with this architecture, as we checked for proteins present in both the UNION interactome and DG set, thus establishing a feedback loop of the type: interaction with $\mathcal{N} F-\kappa B$ pathway $\rightarrow$ transcription factor activation $\rightarrow$ transcriptional regulation $\rightarrow$ interaction with $\mathcal{N} F-\kappa B$ pathway (Table 4). Concerning such feedbacks, we report three cases that were correctly captured by our analysis. The Tumor suppressor protein p53 -that appears among the "feedback" proteins- can be transcriptionally induced by NF- $\kappa \mathrm{B}$ [103-105], among others. On its side, p53 can interfere with NF$\mathrm{\kappa B}$ activity $[106,107]$ thus creating a sort of negative feedback loop between the two factors. The two factors not only interact with each other, but also cooperate or compete (depending upon circumstances) to activate downstream genes [108,109]. The 
Table 4. "Feedback" genes and related proteins (protein ID alphabetical order).

\begin{tabular}{|c|c|c|}
\hline Protein ID & Protein Description & NCBI gene name \\
\hline ANDR & Androgen receptor & $A R$ \\
\hline BCL3 & B-cell lymphoma 3-encoded protein & $\mathrm{BCL3}$ \\
\hline BIRC4 & Baculoviral IAP repeat-containing protein 4 & BIRC4 \\
\hline BLNK & B-cell linker protein & BLNK \\
\hline BTK & Tyrosine-protein kinase BTK & BTK \\
\hline CAV1 & Caveolin-1 & CAV1 \\
\hline CFLAR & CASP8 and FADD-like apoptosis regulator & CFLAR \\
\hline EGR1 & Early growth response protein 1 & EGR1 \\
\hline ELF3 & ETS-related transcription factor Elf-3 & ELF3 \\
\hline ERBB2 & Receptor tyrosine-protein kinase erbB-2 & ERBB2 \\
\hline GCR & Glucocorticoid receptor & NR3C1 \\
\hline HS90A & Heat shock protein HSP 90-alpha & HSP90AA1 \\
\hline IKBA & NF-kappa-B inhibitor alpha & NFKBIA \\
\hline IKBE & NF-kappa-B inhibitor epsilon & NFKBIE \\
\hline IKBZ & NF-kappa-B inhibitor zeta & NFKBIZ \\
\hline IL2RA & Interleukin-2 receptor alpha chain & IL2RA \\
\hline IL32 & Interleukin-32 & IL32 \\
\hline IRF1 & Interferon regulatory factor 1 & IRF1 \\
\hline IRF2 & Interferon regulatory factor 2 & IRF2 \\
\hline KISS1 & Metastasis-suppressor KiSS-1 & KISS1 \\
\hline LYSC & Lysozyme C & LYZ \\
\hline MYC & Myc proto-oncogene protein & MYC \\
\hline NFKB1 & Nuclear factor NF-kappa-B p105 subunit & NFKB1 \\
\hline NFKB2 & Nuclear factor NF-kappa-B p100 subunit & NFKB2 \\
\hline NOD2 & Nucleotide-binding oligomerization domain-containing protein 2 & NOD2 \\
\hline NUAK2 & NUAK family SNF1-like kinase 2 & NUAK2 \\
\hline OLR1 & Oxidized low-density lipoprotein receptor 1 & OLR1 \\
\hline P53 & Tumor suppressor gene $\mathrm{p} 53$ & TP53 \\
\hline PRGR & Progesterone receptor & PGR \\
\hline PSA2 & Proteasome subunit alpha type- 2 & PSMA2 \\
\hline PSB9 & Proteasome subunit beta type- 9 & PSMB9 \\
\hline PTEN & Phosphatidylinositol-3,4,5-trisphosphate 3-phosphatase PTEN & PTEN \\
\hline REL & C-Rel proto-oncogene protein & REL \\
\hline RELB & Transcription factor RelB & RELB \\
\hline RIPK2 & Receptor-interacting serine/threonine-protein kinase 2 & RIPK2 \\
\hline TCAM1 & TIR domain-containing adapter molecule 1 & TICAM1 \\
\hline TERT & Telomerase reverse transcriptase & TERT \\
\hline TGM2 & Protein-glutamine gamma-glutamyltransferase 2 & TGM2 \\
\hline TIFA & TRAF-interacting protein with FHA domain-containing protein $\mathrm{A}$ & TIFA \\
\hline TLR2 & Toll-like receptor 2 & TLR2 \\
\hline TLR9 & Toll-like receptor 9 & TLR9 \\
\hline TNAP3 & Tumor necrosis factor, alpha-induced protein 3 & TNFAIP3 \\
\hline TNF15 & Tumor necrosis factor ligand superfamily member 15 & TNFSF15 \\
\hline TNIP1 & TNFAIP3-interacting protein 1 & TNIP1 \\
\hline TNIP3 & TNFAIP3-interacting protein 3 & TNIP3 \\
\hline TRAF1 & TNF receptor-associated factor 1 & TRAF1 \\
\hline TRAF2 & TNF receptor-associated factor 2 & TRAF2 \\
\hline TWST1 & Twist-related protein 1 & TWIST1 \\
\hline VIME & Vimentin & VIM \\
\hline
\end{tabular}

$\mathrm{NF}-\mathrm{KB}$ controls the transcription of hundreds of genes. Forty-nine of them code for proteins that belong to the UNION interactome, i.e. that participate in the activation of NF- $\mathrm{KB}$. The circuit "interaction with NF- $\mathrm{KB}$ pathway $\rightarrow$ transcription factor activation $\rightarrow$ transcriptional regulation $\rightarrow$ interaction with NF- $\mathrm{KB}$ pathway" establishes a number of feedback loops that can play a role in the dynamics of the NF- $\mathrm{\kappa B}$ system. In bold the four NF- $\mathrm{\kappa B}$ components which transcription is regulated by NF- $\mathrm{kB}$ itself. doi:10.1371/journal.pone.0032678.t004 


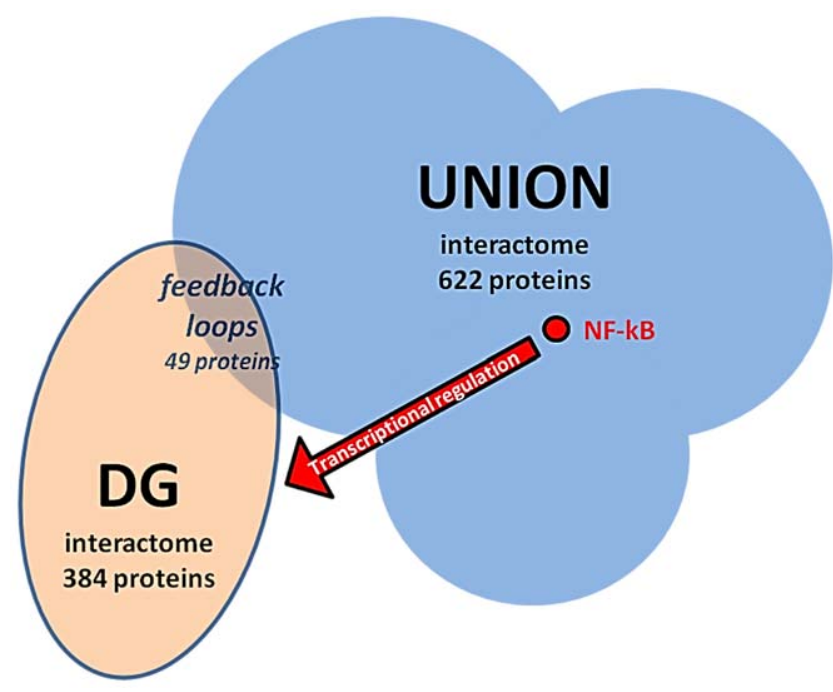

Figure 3. The UNION interactome is composed by 622 proteins, including the five NF-KB subunits. NF-KB is able to regulate the expression of 426 proteins (DG set, see main text). A subset (384 proteins, present in the APID database, out of 426) has been checked for PPIs (see Dataset S1). Forty nine proteins are shared by both the UNION and the DG sets, establishing a feedback loop: "interaction with NF- $\kappa B$ pathway $\rightarrow$ transcription factor activation $\rightarrow$ transcriptional regulation $\rightarrow$ interaction with NF- $\kappa B$ pathway", meaning that $13 \%$ of the identified NF$\kappa B$-regulated genes express proteins that play a direct role in the UNION interactome.

doi:10.1371/journal.pone.0032678.g003

analysis also identified a complex cross-regulatory loop involving NF- $\kappa$ B and PTEN, a "feedback" protein, that may serve to balance their mutually antagonistic functions. Indeed, PTEN is down-regulated by NF- $\kappa \mathrm{B}$ and is able to negatively regulate NF$\kappa \mathrm{B}$, establishing a complex regulation which determines cell survival or apoptosis [110,111]. The "feedback" ubiquitin-editing protein TNAP3 (TNFAIP3) has been described as a key player in the termination of NF- $\kappa \mathrm{B}$ signaling and in controlling NF- $\kappa \mathrm{B}-$ dependent inflammation [112]. In most cell types basal TNAP3 expression is very low but its transcription is rapidly induced upon NF-kB activation. Once expressed, TNAP3 functions as a negative feedback regulator of NF- $\mathrm{KB}$ activation [112].

Based upon these evidences, we propose that a comprehensive and systemic consideration of "feedback" genes may complement important findings in autoregulatory feedback loops [113] leading to a deeper understanding of the complex NF- $\kappa \mathrm{B}$ regulation and dependent inflammation. In this perspective, the observation of a number of feedback loops deserves a deeper systemic and experimental investigation, since these interactions might be potential critical points for the NF- $\mathrm{NB}$ system regulation neglected so far. In this direction, results from this interactome reconstruction can be used as preliminary screening to identify putative key regulators of $\mathrm{NF}-\kappa \mathrm{B}$ system.

In summary, substantial divergences in the composition of the DI, $\mathrm{U}$ and $\mathrm{MC}$ sets open questions about the adequacy and comprehensiveness of classical pathway descriptions and representations, and suggest the participation of a number of proteins one order of magnitude higher than that classically taken into consideration, thus transforming the concept of pathway from an isolated entity into an open, unbound one. The map as it is introduced here provides a tool to explore the complexity of the $\mathrm{NF}-\kappa \mathrm{B}$ system and to make useful qualitative predictions regarding key regulators and mediators of its activating signalling cascade, but it is only a first step in this direction. The next steps will be not only the obvious and continuous updates of existing records and newly produced data, but also the charting of the interactome of the different NF- $\mathrm{BB}$ components, and the analysis of interacting proteins taking into account their sub-cellular compartmentalization, which is currently one of most promising perspective for the elucidation of the mechanisms related to ageing [114]. To this regards, it is also plausible that NF- $\kappa \mathrm{B}$ interactome can be differently charted considering as a variable the five NF-кB members, as well as the sub-cellular localisation of its components (e.g. nucleus, organelles, membranes, cytoplasm).

A further important step will consist in charting cell typespecific, and time-dependent interactomes, able to show maps of various cellular functions, given that $\mathrm{NF}-\kappa \mathrm{B}$ has not only a major role in inflammatory status but it has also a crucial role in neuronal cells, for instance in the Schwann cell myelination, at least in mouse models [115]. Dynamic analysis of interactomes is the next fascinating aim, crucial for the better understanding of proteinprotein interactions when data from time-resolved proteomics will be completely available, together with an adequate mathematical and algorithmic contribution [116,117]. This approach could be extremely relevant to definitively disentangle when, where and how protein-protein interactions give their contribution to the different functional levels of cell systems (different types of cells, tissues, different responses to various stimuli etc). To this regard, network inference based on the huge amount of data gathered in the Omics era might represent a successful approach [118].

As a whole, the results of the integrative approach shown and reported here are meant to be used as a starting point to identify new roles of NF- $\kappa \mathrm{B}$ in physiology and diseases. The integrated analysis we performed identified elements and pathways that are not immediately linked to $\mathrm{NF}-\kappa \mathrm{B}$ itself, or not taken into consideration in respect to its regulation and dynamics, and may thus suggest new directions for further studies and analyses.

\section{Supporting Information}

Table S1 Uniprot annotations retrieved and used to populate protein dataset $\mathrm{U}$.

(XLS)

Table S2 gene identifiers extracted from a manually curated list of NF- $\mathrm{BB}-$ downstream genes [13] and from the Transcriptional Regulatory Elements Database (TRED; [83,84]), and related protein unique identifiers (Uniprot IDs) obtained using online ID converter tools [85] used to compile DG dataset.

(XLS)

Table S3 overrepresented KEGG pathways in DI, U, MC and DG datasets.

(XLSX)

Dataset S1 complete Cytoscape network session with full datasets and interactomes.

(RAR)

\section{Acknowledgments}

We apologize to all colleagues who have made important contributions and could not be cited owing to time and space constraints.

\section{Author Contributions}

Conceived and designed the experiments: PT CF. Performed the experiments: PT AT. Analyzed the data: PT AT EB SS MC CF. Contributed reagents/materials/analysis tools: PT AT EB SS MC CF. Wrote the paper: PT AT EB SS MC GF. 


\section{References}

1. Vodovotz Y, Csete M, Bartels J, Chang S, An G (2008) Translational systems biology of inflammation. PLoS Comput Biol 4: e1000014.

2. De Martinis M, Franceschi C, Monti D, Ginaldi L (2005) Inflamm-ageing and lifelong antigenic load as major determinants of ageing rate and longevity. FEBS Lett 579: 2035-2039.

3. Fagiolo U, Cossarizza A, Scala E, Fanales-Belasio E, Ortolani C, et al. (1993) Increased cytokine production in mononuclear cells of healthy elderly people. Eur J Immunol 23: 2375-2378.

4. Alberti S, Cevenini E, Ostan R, Capri M, Salvioli S, et al. (2006) Agedependent modifications of Type 1 and Type 2 cytokines within virgin and memory CD4+ T cells in humans. Mech Ageing Dev 127: 560-566.

5. Wikby A, Nilsson BO, Forsey R, Thompson J, Strindhall J, et al. (2006) The immune risk phenotype is associated with IL-6 in the terminal decline stage: findings from the Swedish NONA immune longitudinal study of very late life functioning. Mech Ageing Dev 127: 695-704.

6. Vescovini R, Biasini C, Fagnoni FF, Telera AR, Zanlari L, et al. (2007) Massive load of functional effector CD4+ and CD8+ $\mathrm{T}$ cells against cytomegalovirus in very old subjects. J Immunol 179: 4283-4291.

7. Ostan R, Bucci L, Capri M, Salvioli S, Scurti M, et al. (2008) Immunosenescence and immunogenetics of human longevity. Neuroimmunomodulation 15: 224-240.

8. Franceschi C, Bonafè M, Valensin S, Olivieri F, De Luca M, et al. (2000) Inflamm-aging. An evolutionary perspective on immunosenescence. Ann N Y Acad Sci 908: 244-254.

9. Franceschi C, Capri M, Monti D, Giunta S, Olivieri F, et al. (2007) Inflammaging and anti-inflammaging: a systemic perspective on aging and longevity emerged from studies in humans. Mech Ageing Dev 128: 92-105.

10. Cevenini E, Bellavista E, Tieri P, Castellani G, Lescai F, et al. (2010) Systems Biology and Longevity: An Emerging Approach to Identify Innovative AntiAging Targets and Strategies. Current Pharmaceutical Design. pp 802-813.

11. Vescovini R, Biasini C, Telera AR, Basaglia M, Stella A, et al. (2010) Intense antiextracellular adaptive immune response to human cytomegalovirus in very old subjects with impaired health and cognitive and functional status. J Immunol 184: 3242-3249.

12. Pahl H (1999) Activators and target genes of Rel/NF-kappaB transcription factors. Oncogene 18: 6853-6866.

13. Gilmore T (2010) Rel/NF-kappaB Transcription Factors. Boston.

14. Perkins N (2007) Integrating cell-signalling pathways with NF-kappaB and IKK function. Nat Rev Mol Cell Biol 8: 49-62.

15. Lenardo M, Baltimore D (1989) NF-kappa B: a pleiotropic mediator of inducible and tissue-specific gene control. Cell 58: 227-229.

16. Hoffmann A, Baltimore D (2006) Circuitry of nuclear factor kappaB signaling. Immunol Rev 210: 171-186.

17. Schmitz M, Mattioli I, Buss H, Kracht M (2004) NF-kappaB: a multifaceted transcription factor regulated at several levels. Chembiochem 5: 1348-1358.

18. Wong E, Tergaonkar V (2009) Roles of NF-kappaB in health and disease: mechanisms and therapeutic potential. Clin Sci (Lond) 116: 451-465.

19. Ben-Neriah Y, Karin M (2011) Inflammation meets cancer, with NF- $\mathrm{KB}$ as the matchmaker. Nat Immunol 12: 715-723.

20. Editorial (2011) Celebrating 25 years of NF-кB. Nat Immunol 12: 681

21. Baltimore D (2011) NF- $\mathrm{BB}$ is 25. Nat Immunol 12: 683-685.

22. Fraser I, Germain R (2009) Navigating the network: signaling cross-talk in hematopoietic cells. Nat Immunol 10: 327-331.

23. Friedman A, Perrimon N (2007) Genetic screening for signal transduction in the era of network biology. Cell 128: 225-231.

24. Boutros M, Ahringer J (2008) The art and design of genetic screens: RNA interference. Nat Rev Genet 9: 554-566.

25. Bhattacharya SK, Gomes J, Cebulla CM (2010) Toward failure analyses in systems biology. Wiley Interdisciplinary Reviews: Systems Biology and Medicine 9999: n/a.

26. Caron E, Ghosh S, Matsuoka Y, Ashton-Beaucage D, Therrien M, et al. (2010) A comprehensive map of the mTOR signaling network. Mol Syst Biol 6: 453.

27. Wu G, Zhu L, Dent JE, Nardini G (2010) A comprehensive molecular interaction map for rheumatoid arthritis. PLoS One 5: e10137.

28. Bhalla U, Iyengar R (1999) Emergent properties of networks of biological signaling pathways. Science 283: 381-387.

29. Bhalla U (2003) Understanding complex signaling networks through models and metaphors. Prog Biophys Mol Biol 81: 45-65.

30. Ivakhno S, Armstrong J (2007) Non-linear dimensionality reduction of signaling networks. BMC Syst Biol 1: 27.

31. Oeckinghaus A, Hayden MS, Ghosh S (2011) Crosstalk in NF-kB signaling pathways. Nat Immunol 12: 695-708.

32. Smale ST (2011) Hierarchies of NF- $\mathrm{KB}$ target-gene regulation. Nat Immunol 12: $689-694$.

33. Killcoyne S, Carter G, Smith J, Boyle J (2009) Cytoscape: a community-based framework for network modeling. Methods Mol Biol 563: 219-239.

34. Shannon P, Markiel A, Ozier O, Baliga N, Wang J, et al. (2003) Cytoscape: a software environment for integrated models of biomolecular interaction networks. Genome Res 13: 2498-2504.

35. Yeung N, Cline M, Kuchinsky A, Smoot M, Bader G (2008) Exploring biological networks with Cytoscape software. Curr Protoc Bioinformatics Chapter 8: Unit 8.13 .
36. Tieri P, de la Fuente A, Termanini A, Franceschi C (2011) Integrating omics data for signaling pathways, interactome reconstruction, and functional analysis. Methods Mol Biol 719: 415-433.

37. Prieto C, De Las Rivas J (2006) APID: Agile Protein Interaction DataAnalyzer. Nucleic Acids Res 34: W298-302.

38. Hernandez-Toro J, Prieto C, De las Rivas J (2007) APID2NET: unified interactome graphic analyzer. Bioinformatics 23: 2495-2497.

39. Al-Shahrour F, Díaz-Uriarte R, Dopazo J (2004) FatiGO: a web tool for finding significant associations of Gene Ontology terms with groups of genes. Bioinformatics 20: 578-580.

40. Al-Shahrour F, Minguez P, Vaquerizas JM, Conde L, Dopazo J (2005) BABELOMICS: a suite of web tools for functional annotation and analysis of groups of genes in high-throughput experiments. Nucleic Acids Res 33: W460-464.

41. Medina I, Carbonell J, Pulido L, Madeira SC, Goetz S, et al. (2010) Babelomics: an integrative platform for the analysis of transcriptomics, proteomics and genomic data with advanced functional profiling. Nucleic Acids Res 38: W210-213.

42. Bauer-Mehren A, Rautschka M, Sanz F, Furlong LI (2010) DisGeNET: a Cytoscape plugin to visualize, integrate, search and analyze gene-disease networks. Bioinformatics 26: 2924-2926.

43. Klein TE, Chang JT, Cho MK, Easton KL, Fergerson R, et al. (2001) Integrating genotype and phenotype information: an overview of the PharmGKB project. Pharmacogenetics Research Network and Knowledge Base. Pharmacogenomics J 1: 167-170.

44. Assenov Y, Ramírez F, Schelhorn SE, Lengauer T, Albrecht M (2008) Computing topological parameters of biological networks. Bioinformatics 24: 282-284.

45. Bader GD, Hogue CW (2003) An automated method for finding molecular complexes in large protein interaction networks. BMC Bioinformatics 4: 2.

46. Joy MP, Brock A, Ingber DE, Huang S (2005) High-betweenness proteins in the yeast protein interaction network. J Biomed Biotechnol. pp 96-103.

47. Platzer A, Perco P, Lukas A, Mayer B (2007) Characterization of proteininteraction networks in tumors. BMC Bioinformatics 8: 224.

48. Barkett M, Gilmore T (1999) Control of apoptosis by Rel/NF-kappaB transcription factors. Oncogene 18: 6910-6924.

49. Bell S, Matthews J, Jaffray E, Hay R (1996) I(kappa)B(gamma) inhibits DNA binding of NF-kappaB p50 homodimers by interacting with residues that contact DNA. Mol Cell Biol 16: 6477-6485.

50. Ben-Neriah Y (2002) Regulatory functions of ubiquitination in the immune system. Nat Immunol 3: 20-26.

51. Campbell K, O'Shea J, Perkins N (2006) Differential regulation of NF-kappaB activation and function by topoisomerase II inhibitors. BMC Cancer 6: 101.

52. Chen L, Greene W (2004) Shaping the nuclear action of NF-kappaB. Nat Rev Mol Cell Biol 5: 392-401.

53. Chen Z (2005) Ubiquitin signalling in the NF-kappaB pathway. Nat Cell Biol 7: 758-765.

54. Cohen S, Achbert-Weiner H, Ciechanover A (2004) Dual effects of IkappaB kinase beta-mediated phosphorylation on p105 Fate: SCF(beta-TrCP)dependent degradation and $\mathrm{SCF}($ beta-TrCP)-independent processing. Mol Cell Biol 24: 475-486.

55. Dobrzanski P, Ryseck R, Bravo R (1994) Differential interactions of Rel-NFkappa B complexes with I kappa B alpha determine pools of constitutive and inducible NF-kappa B activity. EMBO J 13: 4608-4616.

56. Donzé O, Deng J, Curran J, Sladek R, Picard D, et al. (2004) The protein kinase PKR: a molecular clock that sequentially activates survival and death programs. EMBO J 23: 564-571.

57. Elliott P, Zollner T, Boehncke W (2003) Proteasome inhibition: a new antiinflammatory strategy. J Mol Med 81: 235-245.

58. Franzoso G, Bours V, Park S, Tomita-Yamaguchi M, Kelly K, et al. (1992) The candidate oncoprotein Bcl-3 is an antagonist of p50/NF-kappa Bmediated inhibition. Nature 359: 339-342.

59. Gilmore T, Gapuzan M, Kalaitzidis D, Starczynowski D (2002) Rel/NF-kappa $\mathrm{B} / \mathrm{I}$ kappa $\mathrm{B}$ signal transduction in the generation and treatment of human cancer. Cancer Lett 181: 1-9.

60. Häcker H, Karin M (2006) Regulation and function of IKK and IKK-related kinases. Sci STKE 2006: re13.

61. Hayden M, Ghosh S (2004) Signaling to NF-kappaB. Genes Dev 18: 2195-2224.

62. Hayden M, West A, Ghosh S (2006) SnapShot: NF-kappaB signaling pathways. Cell 127: 1286-1287.

63. Hinz M, Löser P, Mathas S, Krappmann D, Dörken B, et al. (2001) Constitutive NF-kappaB maintains high expression of a characteristic gene network, including CD40, CD86, and a set of antiapoptotic genes in Hodgkin/ Reed-Sternberg cells. Blood 97: 2798-2807.

64. Ishinaga H, Jono H, Lim J, Kweon S, Xu H, et al. (2007) TGF-beta induces p65 acetylation to enhance bacteria-induced NF-kappaB activation. EMBO J 26: $1150-1162$.

65. Krappmann D, Wegener E, Sunami Y, Esen M, Thiel A, et al. (2004) The IkappaB kinase complex and NF-kappaB act as master regulators of lipopolysaccharide-induced gene expression and control subordinate activation of AP-1. Mol Cell Biol 24: 6488-6500. 
66. Malek S, Chen Y, Huxford T, Ghosh G (2001) IkappaBbeta, but not IkappaBalpha, functions as a classical cytoplasmic inhibitor of NF-kappaB dimers by masking both NF-kappaB nuclear localization sequences in resting cells. J Biol Chem 276: 45225-45235.

67. Malek S, Huang D, Huxford T, Ghosh S, Ghosh G (2003) X-ray crystal structure of an IkappaBbeta x NF-kappaB p65 homodimer complex. J Biol Chem 278: 23094-23100.

68. Moorthy A, Savinova O, Ho J, Wang V, Vu D, et al. (2006) The $20 \mathrm{~S}$ proteasome processes NF-kappaB1 p105 into p50 in a translation-independent manner. EMBO J 25: 1945-1956.

69. Pasparakis M, Luedde T, Schmidt-Supprian M (2006) Dissection of the NFkappaB signalling cascade in transgenic and knockout mice. Cell Death Differ 13: 861-872.

70. Pham L, Tamayo A, Yoshimura L, Lin-Lee Y, Ford R (2005) Constitutive NFkappaB and NFAT activation in aggressive B-cell lymphomas synergistically activates the CD154 gene and maintains lymphoma cell survival. Blood 106: 3940-3947.

71. Rodriguez M, Thompson J, Hay R, Dargemont C (1999) Nuclear retention of IkappaBalpha protects it from signal-induced degradation and inhibits nuclear factor kappaB transcriptional activation. J Biol Chem 274: 9108-9115.

72. Saccani S, Pantano S, Natoli G (2003) Modulation of NF-kappaB activity by exchange of dimers. Mol Cell 11: 1563-1574.

73. Salminen A, Huuskonen J, Ojala J, Kauppinen A, Kaarniranta K, et al. (2008) Activation of innate immunity system during aging: NF-kB signaling is the molecular culprit of inflamm-aging. Ageing Res Rev 7: 83-105.

74. Schmitz M, Baeuerle $\mathrm{P}$ (1991) The p65 subunit is responsible for the strong transcription activating potential of NF-kappa B. EMBO J 10: 3805-3817.

75. Taylor I, Wrana J (2008) SnapShot: The TGFbeta pathway interactome. Cell 133: 378.e371.

76. Thompson J, Phillips R, Erdjument-Bromage H, Tempst P, Ghosh S (1995) I kappa B-beta regulates the persistent response in a biphasic activation of NFkappa B. Cell 80: 573-582.

77. Ward K, Zhang K, Somasiri A, Roskelley C, Schrader J (2004) Expression of activated M-Ras in a murine mammary epithelial cell line induces epithelialmesenchymal transition and tumorigenesis. Oncogene 23: 1187-1196.

78. Wegener E, Oeckinghaus A, Papadopoulou N, Lavitas L, SchmidtSupprian M, et al. (2006) Essential role for IkappaB kinase beta in remodeling Carma1-Bcl10-Malt1 complexes upon T cell activation. Mol Cell 23: 13-23.

79. Weil R, Israël A (2006) Deciphering the pathway from the TCR to NFkappaB. Cell Death Differ 13: 826-833.

80. Wertz I, O'Rourke K, Zhou H, Eby M, Aravind L, et al. (2004) Deubiquitination and ubiquitin ligase domains of A20 downregulate NF-kappaB signalling. Nature 430: 694-699.

81. Whiteside S, Epinat J, Rice N, Israël A (1997) I kappa B epsilon, a novel member of the I kappa B family, controls RelA and cRel NF-kappa B activity. EMBO J 16: 1413-1426.

82. Wulczyn F, Naumann M, Scheidereit C (1992) Candidate proto-oncogene bcl3 encodes a subunit-specific inhibitor of transcription factor NF-kappa B. Nature 358: 597-599.

83. Zhao F, Xuan Z, Liu L, Zhang M (2005) TRED: a Transcriptional Regulatory Element Database and a platform for in silico gene regulation studies. Nucleic Acids Res 33: D103-107

84. Jiang C, Xuan Z, Zhao F, Zhang M (2007) TRED: a transcriptional regulatory element database, new entries and other development. Nucleic Acids Res 35: D137-140.

85. Alibés A, Yankilevich P, Cañada A, Díaz-Uriarte R (2007) IDconverter and IDClight: conversion and annotation of gene and protein IDs. BMC Bioinformatics 8: 9 .

86. Peters RT, Liao SM, Maniatis T (2000) IKKepsilon is part of a novel PMAinducible IkappaB kinase complex. Mol Cell 5: 513-522.

87. Malinin NL, Boldin MP, Kovalenko AV, Wallach D (1997) MAP3K-related kinase involved in NF-kappaB induction by TNF, CD95 and IL-1. Nature 385: 540-544.

88. Bista P, Zeng W, Ryan S, Bailly V, Browning JL, et al. (2010) TRAF3 controls activation of the canonical and alternative NFkappaB by the lymphotoxin beta receptor. J Biol Chem 285: 12971-12978.

89. Nourbakhsh M, Hauser H (1999) Constitutive silencing of IFN-beta promoter is mediated by NRF (NF-kappaB-repressing factor), a nuclear inhibitor of NFkappaB. EMBO J 18: 6415-6425.

90. Wu H, Arron JR (2003) TRAF6, a molecular bridge spanning adaptive immunity, innate immunity and osteoimmunology. Bioessays 25: 1096-1105.

91. Hedayat M, Netea MG, Rezaei N (2011) Targeting of Toll-like receptors: a decade of progress in combating infectious diseases. Lancet Infect Dis 11: $702-712$.
92. Hehlgans T, Pfeffer K (2005) The intriguing biology of the tumour necrosis factor/tumour necrosis factor receptor superfamily: players, rules and the games. Immunology 115: 1-20.

93. Ruland J (2011) Return to homeostasis: downregulation of NF- $\mathrm{KB}$ responses. Nat Immunol 12: 709-714.

94. Sato S, Sanjo H, Takeda K, Ninomiya-Tsuji J, Yamamoto M, et al. (2005) Essential function for the kinase TAK 1 in innate and adaptive immune responses. Nat Immunol 6: 1087-1095.

95. Csete M, Doyle J (2004) Bow ties, metabolism and disease. Trends in Biotechnology 22: 446-450.

96. Yang SK, Wang YC, Chao CC, Chuang YJ, Lan CY, et al. (2010) Dynamic cross-talk analysis among TNF-R, TLR-4 and IL-1R signalings in TNFalphainduced inflammatory responses. BMC Med Genomics 3: 19.

97. Wang YC, Chen BS (2010) Integrated cellular network of transcription regulations and protein-protein interactions. BMC Syst Biol 4: 20.

98. Ottaviani E (2011) Evolution of immune-neuroendocrine integration from an ecological immunology perspective. Cell Tissue Res 344: 213-215.

99. Ottaviani E, Malagoli D, Capri M, Franceschi C (2008) Ecoimmunology: is there any room for the neuroendocrine system? Bioessays 30: 868-874.

100. Kitano H, Oda K (2006) Robustness trade-offs and host-microbial symbiosis in the immune system. Mol Syst Biol 2: 2006.0022.

101. Tieri P, Grignolio A, Zaikin A, Mishto M, Remondini D, et al. (2010) Network, degeneracy and bow tie integrating paradigms and architectures to grasp the complexity of the immune system. Theor Biol Med Model 7: 32.

102. Vitali S, Glattfelder JB, Battiston S (2011) The network of global corporate control. PLoS One 6: e25995.

103. Wu H, Lozano G (1994) NF-kappa B activation of p53. A potential mechanism for suppressing cell growth in response to stress. J Biol Chem 269: 20067-20074.

104. Pei XH, Nakanishi Y, Takayama K, Bai F, Hara N (1999) Benzo[a]pyrene activates the human p53 gene through induction of nuclear factor kappaB activity. J Biol Chem 274: 35240-35246.

105. Qin C, Nguyen T, Stewart J, Samudio I, Burghardt R, et al. (2002) Estrogen up-regulation of p53 gene expression in MCF-7 breast cancer cells is mediated by calmodulin kinase IV-dependent activation of a nuclear factor kappaB/ CGAAT-binding transcription factor-1 complex. Mol Endocrinol 16: 1793-1809.

106. Ikeda A, Sun X, Li Y, Zhang Y, Eckner R, et al. (2000) p300/CBP-dependent and -independent transcriptional interference between NF-kappaB RelA and p53. Biochem Biophys Res Commun 272: 375-379.

107. Jeong SJ, Radonovich M, Brady JN, Pise-Masison CA (2004) HTLV-I Tax induces a novel interaction between p65/RelA and p53 that results in inhibition of p53 transcriptional activity. Blood 104: 1490-1497.

108. Ravi R, Mookerjee B, van Hensbergen Y, Bedi GC, Giordano A, et al. (1998) p53-mediated repression of nuclear factor-kappaB RelA via the transcriptional integrator p300. Cancer Res 58: 4531-4536.

109. Schneider G, Henrich A, Greiner G, Wolf V, Lovas A, et al. (2010) Cross talk between stimulated NF-kappaB and the tumor suppressor p53. Oncogene 29: 2795-2806.

110. Vasudevan KM, Gurumurthy S, Rangnekar VM (2004) Suppression of PTEN expression by NF-kappa B prevents apoptosis. Mol Cell Biol 24: 1007-1021.

111. Ying H, Elpek KG, Vinjamoori A, Zimmerman SM, Chu GC, et al. (2011) Pten is a major tumor suppressor in pancreatic ductal adenocarcinoma and regulates an NF-kB-cytokine network. Cancer Discov 1: 158-169.

112. Vereecke L, Beyaert R, van Loo G (2009) The ubiquitin-editing enzyme A20 (TNFAIP3) is a central regulator of immunopathology. Trends Immunol 30: 383-391.

113. Renner F, Schmitz ML (2009) Autoregulatory feedback loops terminating the NF-kappaB response. Trends Biochem Sci 34: 128-135.

114. Simkó GI, Gyurkó D, Veres DV, Nánási T, Csermely P (2009) Network strategies to understand the aging process and help age-related drug design. Genome Med 1: 90.

115. Chen Y, Wang H, Yoon SO, Xu X, Hottiger MO, et al. (2011) HDACmediated deacetylation of NF- $\mathrm{KB}$ is critical for Schwann cell myelination. Nat Neurosci 14: 437-441.

116. Bhattacharya SK (2010) Towards a matrix mechanics framework for dynamic protein network. Syst Synth Biol 4: 139-144.

117. Cheong R, Hoffmann A, Levchenko A (2008) Understanding NF-kappaB signaling via mathematical modeling. Mol Syst Biol 4: 192

118. Lecca P, Nguyen TP, Priami C, Quaglia P (2011) Network inference from time-dependent Omics data. Methods Mol Biol 719: 435-455. 